\title{
ATUALIDADE E FECUNDIDADE DA OBRA DE DURKHEIM NA SOCIOLOGIA DA EDUCAÇÃO'
}

\section{THE PRESENT RELEVANCE AND FRUITFULNESS OF DURKHEIM'S WORK ON THE SOCIOLOGY OF EDUCATION}

\author{
Mesa-redonda ${ }^{2}$ coordenada por Jean-Claude Filloux \\ com a participação de \\ Pierre Bourdieu, Michel Eliard e Aïssa Kadri
}

Jean-Claude FILLOUX - Esta mesa-redonda trata de um tema preciso. Ele resume-se em dois termos: a palavra fecundidade e a palavra atualidade. Fecundidade: questiona o destino científico do modo de análise que foi elaborado por Durkheim; de certa maneira, é uma questão também de filiação. Atualidade: o que quer dizer - agora, neste momento - ser durkheimiano quando se trabalha como sociólogo no campo da educação? Isso posto - e dirigindo-me aos participantes desta mesa-redonda -, é por meio de suas específicas relações com a sociologia que os convido a se posicionarem em relação a estas duas ordens de questões: fecundidade e atualidade.

Michel Eliard é professor de sociologia na Universidade de Toulouse-Le Mirail. Pierre Bourdieu, vocês sabem, é professor no Collège de France. Aïsse Kadri, que é de origem argelina, ensina na Universidade de Paris VIII.

$\mathrm{Eu}$ vou pedir que cada um fale durante aproximadamente dez minutos, para tentarem responder num primeiro momento às questões que foram colocadas. Num segundo momento, assim espero, haverá uma discussão entre meus três vizinhos. Também

1. 0 presente texto, traduzido por José Benevides Queiroz, é uma mesa-redonda que se encontra em CARDI, F.; PLANTIER, J. (Orgs.). Durkheim, sociologue de l'éducation, Paris: L'Harmattan, 1993. A Revista Pós Ciências Sociais agradece a editora L'Harmattan por ter lhe cedido os direitos de publicá-lo em português. 2. Esta mesa-redonda encerrou as Jornadas de estudo sobre Durkheim e a sociologia da educação, ocorridas nos dias 15 e 16 de outubro de 1992, na Sorbonne, organizadas pelo Instituto Nacional de Pesquisa Pedagógica e pelas universidades Lumière-Lyon 2 e Rennes 2. (N.T.)

3. Também participariam da mesa-redonda Roger Establet e Jean-Claude Chamboredon, mas eles não puderam comparecer. (N.T.) 
espero que haja numerosas questões que venham, como se diz, do auditório. Assim, inicialmente, conforme acordado previamente, passo a palavra a Michel Eliard. Em seguida será Pierre Bourdieu e, por fim, Aïsse Kadri.

Michel ELIARD - Hoje, como podemos ser durkheimianos na sociologia da educação? A resposta a essa questão não é simples, sobretudo para alguém que não se sente muito durkheimiano, como no meu caso. Portanto, serei tentado a responder que, para abordar de maneira pertinente os problemas da educação hoje, faz-se necessário operar uma ruptura com Durkheim. Na realidade, a resposta é mais complicada na medida em que o homem e a obra parecem atravessados por paradoxos.

Apesar de ser bastante alérgico a esta sociologia moral, a esta sociologia da integração social que parece caracterizar a produção dominante de Durkheim e que dá uma orientação muito conservadora à maior parte de seus escritos sobre educação, podemos nos sentir muito durkheimianos quando lemos as penetrantes análises de $A$ evolução pedagógica na França, que nos inspira para interpretar as realidades atuais.

A fecundidade de sua sociologia da educação nos conduz inicialmente às inúmeras áreas que semeou e que foram fertilizadas nos anos 1960/1970, ao mesmo tempo em continuidade e em ruptura com suas análises. Talvez seja uma feliz coincidência sua nomeação para uma cadeira de pedagogia, pois, se acreditarmos em Marcel Mauss, seus cursos de ciência da educação eram para ele um peso que o desviava de seus interesses fundamentais, que eram a familia e a moral. Feliz coincidência, portanto, que nos legou suas análises particularmente fecundas sobre a história do ensino secundário, porém não fez delas a base de sua teoria da educação, talvez porque elas se encontrassem um pouco em contradição com seus postulados organicistas. Particularmente, penso sobre sua interpretação das transformações pedagógicas do Renascimento, que relaciona com as transformações sociais e econômicas e com as relações entre as classes.

Durkheim aplica também essa análise à Revolução Francesa, a qual saudava, como Jaurès, por sua grandiosa obra em matéria escolar. Diversamente, para seu tempo, aquele do período da edificação da escola pública, ele produz uma teoria da educação conforme os interesses da burguesia republicana, conforme seus objetivos de modernização do Estado e do consenso entre as classes.

Isso me leva a sublinhar um outro paradoxo, a propósito de sua concepção de democracia. Incontestavelmente, Durkheim era um democrata. Ao mesmo tempo, ele desenvolveu uma teoria da democracia e do Estado que é muito pouco republicana e que dá às suas análises sobre as relações entre a escola e o Estado uma orientação que rompe com certa tradição do Iluminismo, em particular com aquela de Condorcet. Dessa teoria do Estado, nos deixou alguns elementos esparsos no curso $O$ Socialismo, em suas críticas de obras e, sobretudo, nos capítulos sobre a moral cívica de Lições de Sociologia. Essa teoria se opõe à concepção de democracia saída da tradição da Revolução Francesa, em particular às ideias de soberania do povo e de democracia representativa em favor de uma democracia social fundada sobre os grupos profissionais, sobre a estrutura funcional da sociedade, forma corporativa que se opõe à eleição de deputados com mandatos a qual via, sobretudo, como um modo de funcionamento anárquico e ineficaz da representação na- 
cional. Com efeito, ele escreve: "quando o Estado pensa e decide, não é necessário dizer que este é a sociedade que pensa e se decide por ele, mas que ele pensa e se decide por ela. Não é um simples instrumento de canalização e de concentração. Ele é, num certo sentido, o centro organizador dos próprios subgrupos"4. Essa concepção do Estado que pensa pela coletividade vai de par com uma teoria da educação que dá prioridade à integração do indivíduo ao corpo social sobre a emancipação individual, o que explica a enorme importância atribuída à educação moral, à transmissão dos valores declarados comuns.

Estabelece-se frequentemente uma continuidade entre Condorcet e Durkheim. Se pudermos estabelecer uma filiação, esta se dá na medida em que ambos os dois foram construtores de uma instrução pública. Porém, enquanto o primeiro ressalta o papel do conhecimento na formação de cidadãos autônomos e livres, o segundo afirma o primado da educação para integrar-se ao corpo social, aos interesses do qual tudo deve ser subordinado. Tanto Condorcet me parece moderno e atual, quanto Durkheim, um pensador da estabilidade e da conservação das relações sociais existentes. E este Durkheim tem uma fecundidade inegável entre as correntes corporativas.

Desejaria terminar ressaltando outro paradoxo. A sociologia da educação dos anos 1960/1970 se construiu, em grande parte, sobre uma base durkheimiana. A sociologia das desigualdades, em particular, apegouse em mostrar que a igualdade formal não era senão uma nova máscara da desigualdade social. Contudo, me parece que entre as análises que Durkheim só esboçou a esse respeito e as interpretações da sociologia da educação contemporânea operou-se um deslocamento que é, talvez, útil sublinhar. Quando Durkheim define seu ideal de sociedade democrática, fundada sobre uma justa hierarquia do mérito, encontra-se em conformidade com os interesses da burguesia republicana da época. Ele não desconhecia, no entanto, a desigualdade desta meritocracia consagrada: “no fundo, [escreve ele], não será que as desigualdades de mérito também não são desigualdades fortuitas, desigualdades de nascença pelas quais não é justo, em certo sentido, atribuir a responsabilidade aos homens? Não nos parece equitativo que um homem seja mais bem tratado socialmente porque nasceu de uma pessoa rica ou de elevada dignidade. Será mais equitativo que um homem seja mais bem tratado socialmente por ter nascido de um pai mais inteligente, nas melhores condições morais?"5.

Também Durkheim atribuía à educação uma importância determinante no estabelecimento das possibilidades de igualar "as condições exteriores da luta”, mas as raízes dessa desigualdade deviam ser procuradas na organização da sociedade e não no funcionamento da escola: "a transmissão hereditária da riqueza basta para tornar muito desiguais as condições exteriores nas quais a luta se processa" ${ }^{6}$ assim já escrevia em Da divisão do trabalho social. Sua proposta de suprimir a herança era, sem dúvida, ilusória e irrisória, mas não tinha o mérito de designar o lugar de uma solução possível do lado das relações sociais, e não do lado da escola, que não podia, por si mesma, ir além dessas relações?

4. DURKHEIM, E. Leçons de Sociologie. Paris: PUF, 1950, p. 61.

5. DURKHEIM, 1950, p. 258.

6. Idem. De la division du travail social. 8e édition. Paris: PUF, 1967, p. 371-372. (N.T.) 
Substituindo a noção de igualdade das chances por aquela de igualdade dos direitos, a sociologia da educação concentrou a atenção sobre a escola, que se encarregou de realizar - ou que se tornou responsável por não realizar - a igualdade de chances numa sociedade desigual.

A democratização da escola, seguramente, duplicou-se de medidas visando a salvaguardar a hierarquia social, mas, como já indicava Condorcet, isto não é necessariamente contraditório com a justiça. Pois as classes populares estão no direito de esperar da burguesia e de seu Estado que eles assegurem a todas as crianças condições de escolarização equitativas, nada mais, nada menos, portanto, condições materiais e pedagógicas iguais.

Quando Durkheim afirma que a escola deve preparar cada indivíduo para ocupar o lugar que lhe compete na divisão do trabalho, em função de suas capacidades, ele legitima uma hierarquia de classes, ele atribui uma função de reprodução social à escola, porém isso se opera numa sociedade na qual cada um pode tentar sua sorte numa corrida comum. Que esta corrida seja uma corrida de desvantagens deve-se "às condições exteriores da luta" e, portanto, as desvantagens não podem ser abolidas somente pelo desenvolvimento da escolaridade. Colocando fortemente a ênfase sobre o papel da escola na reprodução das desigualdades, a sociologia da educação não contribuiu para mascarar o fato de que as reformas escolares acentuaram, depois de três décadas, as disparidades da escolaridade?

Além do que, desenvolvendo as análises sobre a igualdade e a justiça em se tratando da escola, que Durkheim não fez senão esboçar, mostrar-se-ia sem dúvida que os objetivos proclamados da realização da igualdade da política atual do ensino mascaram, na realidade, a exclusão de uma crescente quantidade de alunos, essencialmente de origem popular. Por exemplo, o objetivo aparentemente democrático de ampliar o acesso ao baccalauréat ${ }^{7}$ para o patamar de $80 \%$ de uma classe de concludentes ${ }^{8}$ não corre o risco de conduzir - desde que acompanhado de um desaparecimento progressivo da área técnica que permite obter o diploma de nível $\mathrm{V}$-, à marginalização de jovens para os quais esta qualificação constituía uma garantia social?

Pierre BOURDIEU - Eu vou continuar a reflexão de Michel Eliard tentando responder às duas questões que foram colocadas: o que é ser um durkheimiano e o que o durkheimianismo pode legar à atualidade?

Para responder a essas duas questões, vou começar por lembrar, a título de exemplo, de um uso que fiz a um certo momento de um modo de pensar tipicamente durkheimiano e mostrar que, bizarramente, esse modo de pensar o próprio Durkheim jamais empregou quando tratou da educação. Assim, veremos que não é simples saber o que é ser durkheimiano já que podemos tratar de Durkheim sobre um terreno onde o próprio Durkheim não se fez Durkheim. Penso que poderíamos fazer a mesma coisa com Marx. As questões: "0 que é ser durkheimiano?" ou “O que é ser marxista?" são questões extremamente difíceis, e creio que é importante saber se queremos evitar que essas noções funcionem como etiquetas classifi-

7. Exame nacional francês que permite o acesso ao ensino superior. (N.T.)

8. 0 objetivo tornou-se 100\% no relatório do Sr. Pinaud-Valencienne, presidente da Schneider Eletric, ao ministro da educação. 
catórias ou como princípios de divisão mais política do que científica. Eis, grosso modo, a intenção de minha intervenção.

0 exemplo que tenho em mente é o estudo que fiz, há alguns anos, e que publiquei com o título As categorias do entendimento professoral. É um estudo tipicamente durkheimiano, já que tentei fazer, em relação dos professores franceses dos anos 1970, um estudo análogo àquele que Mauss e Durkheim fizeram no famoso texto As formas primitivas de classificação. Tentei, a partir das apreciações professorais, dos julgamentos que os professores fazem na margem das cópias ou dos boletins escolares, extrair os princípios de classificação implícitos, em particular o sistema de oposições classificatórias, o sistema de adjetivos antagonistas, que os professores utilizam em sua prática pedagógica. Portanto, tentei extrair as formas escolares de classificação, como Durkheim extraíra das formas primitivas de classificação. Não repetirei em detalhe a análise, mas penso que o projeto é tipicamente durkheimiano (poderíamos dizer também kantiano): este projeto consiste em tentar apreender o que poderíamos chamar de transcendentais, isto é, de formas a priori de classificação que os sujeitos sociais fazem uso em suas percepções, em suas avaliações do mundo e em suas práticas. A diferença entre Durkheim e Kant - Durkheim a explica muito claramente em As formas elementares da vida religiosa - é que, para Kant, estas formas a priori eram universais, coextensivas à humanidade; para Durkheim e Mauss elas eram históricas e produzidas num e por um certo tipo de condições históricas. Durkheim formulou uma hipótese muito forte segundo a qual essas classificações eram a reprodução - entre aspas, "no cérebro" - das estruturas sociais nas quais os seres humanos eram formados, moldados. Retomei esta hipótese extremamente arriscada que, creio, é válida em todo caso e em todos os domínios onde tentei verificá-la; a hipótese de que as ações de classificação (como aquelas que consistem em anotar, destacar, a seriedade, a modéstia, a distinção etc.) implementam princípios de classificação, para uma grande parte inconsciente, que não são dominados senão praticamente, que nunca são compreendidos de maneira sistemática, salvo ao preço de um trabalho de objetivação que compete ao pesquisador, e que estão em correspondência com as estruturas objetivas, por exemplo, no caso dos professores franceses, a estrutura das disciplinas (penso na oposição entre teoria e prática), e todas as estruturas que estão na objetividade da instituição escolar e também na subjetividade dos agentes dessa instituição. Se as instituições são tão difíceis de se transformar (tema muito durkheimiano, uma vez que $A$ evolução pedagógica na França é uma extraordinária história da inércia pedagógica), é precisamente por causa deste tipo de harmonia historicamente estabelecida entre as estruturas sociais, nas quais trabalham os professores, e as estruturas mentais que produzem. E se as crises do sistema escolar, como em 1968, tomam a forma de guerras religiosas e são tão patéticas (elas se assemelham muito com as crises que se observam nas sociedades primitivas quando há mudanças brutais ligadas, por exemplo, à aculturação ou ao contato de civilizações), as estruturas sociais transformadas desordenadamente impactam as estruturas mentais. Ora, não há nada que detestemos mais, creio, do que ver o desordenamento de nossas estruturas mentais. As revoluções simbólicas são aquelas que dizem respeito a coisas consideradas fundamentais. 
Eis, portanto, um exemplo de análise que avalio como ultradurkheimiana. Dito isto, que é durkheimiano, e se é verdade que Durkheim jamais o fez, podemos perguntar: por que ele, que escreveu $A$ evolução pedagógica na França, nunca aplicou no estudo do sistema escolar francês o modo de reflexão que empregou quando tratou das formas primitivas de classificação? Por que ele nunca desejou saber: quais são as formas de classificação destes professores, de onde elas vêm? Coisa um tanto quanto surpreendente quando se sabe que $A$ evolução pedagógica na França é um livro admirável. Como é que Durkheim - esta é uma questão que foi colocada por um historiador americano da educação e de Durkheim que se chama Vogt (esqueci o primeiro nome) - inexplicavelmente parou suas análises, neste caso e em muito outros, à entrada de sua própria sociedade; que tenha inquerido as sociedades primitivas ou arcaicas, consideradas como elementares, bloqueando, portanto, o princípio da compreensão das sociedades modernas, questões que não retomou sobre sua própria sociedade? Há um certo número de operações científıcas, que chamo de reflexivas, que consistem em retornar sobre o mundo científico e sobre o próprio cientista as questões que o cientista coloca para os outros mundos, que Durkheim, e toda sua geração, por razões históricas sem dúvida, raramente praticava.

0 que desejava mostrar com esse exemplo é que não se sabe muito o que quer dizer ser durkheimiano, se é verdade que se pode fazer com Durkheim coisas que Durkheim não fez e que, em certa medida, não podia fazer, dadas as condições sociais de produção de Durkheim e do mundo no qual ele pensava. 0 que me faz desconfiar sempre de pessoas que afirmam: "eu sou durkheimiano" ou "vocês são durkheimia- nos”. Penso que há sempre nas formas de essencialismo (diria a mesma coisa de Marx ou de Max Weber) o perigo de impor um tipo de fechamento, de clausura. De fato, poderia levar mais adiante a análise: que poderia fazer um Durkheim inclinado à reflexividade, isto é, aplicar Durkheim em relação a Durkheim, numa situação como esta que nos encontramos? Ele poderia se perguntar: "o que é um ancestral totêmico?"; "o que é um founding father, como se diz nos Estados Unidos?”; “por que os ancestrais totêmicos estão em luta?”. Nas sociedades que Kadri conhece bem, há lutas entre os netos para herdar o primeiro nome de um avô que tem muito prestígio. Há todos os tipos de disputas acadêmicas que parecem bastante com o que Durkheim nos descreve, e penso que o que nós fizemos a mais, todo pequeno passo que demos a mais em relação a Durkheim, foi, talvez, nesta perspectiva. Ao lado do durkheimianismo sacerdotal, que discute sobre o suicídio, a anomia etc., é necessário defender de uma maneira paradoxal de ser durkheimiano que poderia consistir em aplicar ao mundo acadêmico, ao mundo durkheimiano e ao mundo pós-durkheimiano no qual nos encontramos um modo de pensar durkheimiano. Se desejarem, podemos nos divertir fazendo o seguinte exercício: o que é uma herança? E uma herança acadêmica? Como ela se distribui entre os herdeiros legítimos, os herdeiros estatutários, entre a igreja, a igreja durkheimiana, os guardiães do texto canônico, os comentadores, os leitores etc., aqueles que não fazem outra coisa senão ler os textos, lendo-os repetidas vezes etc., e os heréticos que voltam contra a igreja o texto canônico? Penso que este gênero de análise, que pode parecer lúdico, ou mistificador, é, em minha opinião, o que podemos fazer de mais sério em matéria de episte- 
mologia nas ciências sociais, isto é, fazer preceder todo encontro científico, seminário, curso etc., de uma análise, mesmo sumária, das condições sociais para responder o que foi pedido na questão posta; no caso presente, perguntar-nos o que seria uma análise durkheimiana do que fazemos (isso sabendo que Durkheim não o teria feito).

Aïssa KADRI - Desejaria colocar aqui três reflexões que são, antes, constatações que levantarão numerosas questões: três reflexos que nasceram durante um trabalho de pesquisa que trata particularmente sobre a Escola de Direito de Argel e, de modo mais amplo, sobre o sistema de ensino superior argelino.

Minha primeira reflexão - e não me demorarei sobre este ponto senão para medir o efeito que pôde exercer sobre o presente - é o que poderia qualificar, com uma palavra imprópria, o "impasse" ou, antes, os "impasses" de Durkheim e dos durkheimianos sobre a Argélia em particular, o Magrebe e o Islã em geral ${ }^{9}$.

Em termos de referências, o texto de Masqueray, sobre "La formation des cités chez les populations sédentaires d'Algérie”, assim como aquele de Hanoteau, sobre " $\mathrm{La}$ Kabyle et les coutumes kabyles”, são citados em Da divisão do trabalho social; achamos uma alusão aos trabalhos de Hanote- au e Letourneux em As regras do método sociológico; há também referências a W. Marçais, a Abou l'Hassan e Mawerdi nas contribuições de Durkheim ao L'Année Sociologique a propósito do Magrebe e do Islã. Como podemos ver, muito pouca coisa. Observemos também que, de maneira geral, o L'Année Sociologique dedica pouco espaço ao Islã e ao Magrebe, pelo menos no período de 1898 a 1913.

Com relação aos discípulos de Durkheim, eles pouco estiveram presentes em terras argelinas, pelo menos até os anos 1950. Contudo, dois nomes podem ser vinculados a Durkheim, ainda que suas filiações pareçam bastantes tênues. Edmond Doutté, que foi administrador de uma comuna mista, depois professor da medersa ${ }^{10}$ em Tlemcen e, finalmente, professor na Faculdade de Letras de Argel - não sem dificuldade, por não ter feito um cursus honorum ${ }^{11}$, e René Maunier, que veio para a sociologia e a etnologia através da economia e do direito. Doutté mantém correspondência com o L'Année Sociologique e Maunier escreve seus primeiros artigos na Revue Internationale de Sociologie, dirigida por René Worms, e, concomitantemente, no L'Année Sociologique. Por diferentes que sejam seus percursos, os dois autores podem ser incluídos entre os praticantes. Os dois não permanecerão por muito tempo na Argélia: foram quatro anos

9. Muitos trabalhos mostraram isso, notadamente: VALENSI, L. Le Maghreb vu du centre, as place dans l'école sociologique française. In: VATIN, J. C. et al. Connaissances du Maghreb, sciences sociales et colonisation. Paris: CRESM/CNRS, 1984, p. 227-244; COLONNA, F. Les sciences sociales au Maghreb et le paradigme durkheimien, Paris: Groupe de sociologie politique et morale/EHESS, 1990, multigrain, $15 \mathrm{p}$. 10. 0 termo refere-se a pronuncia em árabe da palavra que corresponde à escola. Em francês, encontra-se grafada do seguinte modo: médersa; traduzimos por medersa seguindo indicação do Vocabulário Ortográfico da Língua Portuguesa, da Academia Brasileira de Letras (ACADEMIA BRASILEIRA DE LETRAS. Vocabulário ortográfico da língua portuguesa. Disponível em: <http://www.academia.org.br/nossa-lingua/ busca- no-vocabulario>). (N.T.) Acesso em: 06 dez. 2015.

11. Sobre Doutté, cf. MASSE, H. Les études árabes en Algérie (1830-1930). Revue Africaine, v. 74, 1933, reeditado em 1980. Alger: O.P.U., p. 208-248. 
para Maunier (1922-1926), que será professor na Faculdade de Direito de Argel. É sobretudo após seu retorno à França, que ele escreve muito. Em 1932, ele publica no L'Année Sociologique um balanço de suas "Recherches sur les échanges rituels en Afrique du Nord"12. Doutté, que publicou L'Islam algérien en 1910, Notes sur l'Islã Maghrébin, Les aïssaouas de Tlemcen, magie et religion en Afrique du nord, deixa a Argélia e suas últimas publicações serão marroquinas. Portanto, os dois eram muito pouco ligados à rede dos durkheimianos - deve ser dito que eles não eram muito reconhecidos.

Quanto aos discípulos autóctones de Durkheim, poucos são ali conhecidos, contrário ao que se passa notadamente no Oriente Médio árabe ${ }^{13}$. Exceto Bencheneb ou Bem Zekri, que de todo modo permanecem desconhecidos, a Argélia não conheceu personalidades de envergadura como Taha Husseïn, o qual marcou a história literária e intelectual do Egito contemporâneo - Husseïn acompanhou os cursos de Durkheim na Sorbonne e defendeu uma tese sobre $L a$ philosophie sociale d'Ibn Khaldoun; nem alguém como Mansour Fahny, que, em 1913, defendeu uma tese orientada por Levy-Bruhl sobre La condition de la femme dans la tradition et l'évolution de l'islamisme, que foi reeditada em 1990 com o título La condition de la femme dans l'Islam e prefaciada por Harbi; ou como Ali Abd El Wahib, que tentou formular uma Théorie sociologique de l'esclavage, em 1913, ou ainda como Bishr Farès, que trabalhou sobre L'honneur chez les arabes avant l'Islam, de 1932; bem como outros que trataram do Islã, da família e do casamento mulçumano.

Outro "impasse": a ausência em Durkheim de reflexões sobre a educação argelina, no momento em que as Leis Ferry são estendidas à Argélia. Se podemos falar de Durkheim “missionário" de Jules Ferry na Alemanha, não encontramos nada em sua obra que trate da imposição do sistema escolar francês sobre a Argélia, numa situação de contato cultural de tipo colonial, no mesmo momento em que ocorre na França um grande debate político acerca do tipo de ensino que deveria ser estabelecido na colônia.

Não obstante, o paradigma durkheimiano me parece fortemente insistente enquanto que as alternativas locais gurvitchianas $^{14}$, khaldounianas ${ }^{15}$ ou marxistas não foram tomadas como referências fundamentais; insistente, ao mesmo tempo, como referência implícita institucionalmente enraizada e como modelo para pensar a sociedade não somente em sua evolução, mas também em sua atualidade: tanto no plano das estruturas sociais - e há, deste ponto de vista, uma certa filiação entre o que escreveu Durkheim e os trabalhos de Robert Montagne, de 1930, sobre os Berberes do Alto-Atlas marroquino e aqueles de Ernest Gellner, em torno de 1964, sobre os santos do Atlas - e no

12. Cf. HENRY, J. R. Approches ethnologiques du droit musulman: l'apport de René Maunier. In: FLORY, M.; HENRY, J. R. L'enseignement du droit musulman. Marseille: CNRS, 1989, p. 132-157.

13. AL AHNAF, M. Sur quelques durkheimiens árabes. Peuples Méditerranéens, Sciences Sociales, Sociétés Arabes, n 54/55, janv.- juin 1991.

14. Que diz respeito ao pensamento de Georges Gurvitch, russo de nascimento, que se radica na França a partir da década de 1920. Criador dos Cahiers Internationaux de Sociologie, Gurvitch exerce certa influência na sociologia francesa dos anos de 1950 até início dos anos 1960. (N.T.)

15. Que se refere ao pensador árabe do século XIV, de origem tunisiana, Ibn Khaldoun. (N.T.) 
que diz respeito às relações entre tradição e modernidade, quanto no plano da análise propriamente institucional.

Nesse sentido, podemos falar de uma atualidade de Durkheim, e diria mesmo de uma fecundidade - o que me conduz a minha segunda reflexão: o paradigma durkheimiano permite pensar o presente da Argélia a partir do passado mais longínquo. Afastando-me da obviedade, desejaria aqui sublinhar a fecundidade da reflexão de Durkheim sobre as instituições e sua força de inércia. Ao me ater na análise do sistema de ensino superior argelino, notadamente após a reforma de 1971, percebi que os estorvos institucionais e estruturais herdados do passado tinham um peso pelo menos tão grande quanto as decisões reformadoras na configuração do sistema e nas transmutações que o afetavam. Para irmos mais rápido, e nesta esquematização há sem dúvida uma provocação, pareciame que a argelização e a arabização do sistema de ensino argelino não mudaram em nada, mas aprofundaram as características passadas do sistema. A ideia fundamental de Durkheim - expressa tanto em $A$ evolução pedagógica na França, como em Educação e sociologia - é que a educação deve ser compreendida "como um conjunto de práticas e de instituições que se organizaram lentamente ao longo do tempo, que são solidárias de todas as outras instituições sociais que as exprimem, que, por conseguinte, não podem ser mudadas à vontade, mas com a própria estrutura da sociedade" ${ }^{16}$. Esta ideia de que não se pode compreender um sistema de ensino, no seu funcionamento e nas suas funções, senão à luz de sua gênese histórica e dos fins que foi levado a assumir em razão do passado, foi completamente esclarecida na análise do caso argelino.

Assim, por exemplo, a hierarquização muito forte entre o árabe e o francês, o atual problema da relação de forças sociolinguísticas, não parece de maneira alguma sub-reptício e encontra seus fundamentos no passado colonial. De fato, há uma espécie de permanência da equação cultural argelina que se coloca, nos mesmos termos, a décadas de distância e em situações históricas completamente diferentes. Há mais que analogias, há homologias de funções.

E não é simplesmente de ordem intuitiva a observação de que o sistema nacional de ensino, à imagem do sistema de ensino colonial, tende, de um lado, a privilegiar sua função ideológica em detrimento de sua função de formação técnica e, de outro, principalmente produzir uma elite cindida sobre o duplo plano de sua relação com a linguagem do ensino e o poder local. A divisão francófona/arabófona permeia assim, desde a imposição do sistema escolar francês à Argélia, toda a história cultural e política do país.

A independência, em relação a esse aspecto, não me parece ser uma transformação da natureza desta oposição, mas, antes, um aprofundamento que vai até à ruptura das contradições que produziram a formação e o desenvolvimento da elite argelina. Não é nem um pouco paradoxal observar que, nos processos atuais, há como que uma imagem invertida daquilo que se definiu na Argélia colonial: a equação cultural permanece a mesma - ocidentalização ou afırmação da própria sociedade -, as forças culturais e até os componentes so- 
ciais são similares, os pressupostos que lhes são associados são os mesmos. Para a elite afrancesada, sua ideologia pró-ocidental; para a elite arabizada, sua influência médio -oriental. Mesmo os efeitos da geopolítica mundial seriam idênticos. A vontade dominante: para uns, dominadora e aculturadora do imperialismo francês; e, para outros, ressurgimento e nova revolução islâmica.

Outro exemplo do que chamo de continuidade com base nos valores da instituição é uma certa hierarquia das disciplinas, aquela que perpetua os valores que presidem o funcionamento do sistema de ensino francês fundado sobre o primado das humanidades clássicas e que perdura aqui sob uma forma degradada, imperfeita. Do mesmo modo, o processo empregado na universidade colonial, expresso por uma instrumentalização dela e por sua permeabilidade à ideologia dominante, encontrou seu aprofundamento, poderíamos afırmar, justamente por reação. A universidade dos anos 1970, na Argélia, defıniu-se claramente por oposição à universidade colonial, amplamente composta por professores que participaram do maio de 68; as diversas áreas do ensino desenvolveram-se sobre uma base marxista empobrecida, banhada num terceiro-mundismo e, de modo algum, temperada por um militantismo fortemente engajado. Nessa recusa que tomava a forma do que recusava, havia germes do que viria a seguir. A rejeição seletiva de certas ciências sociais e humanas, como a etnologia, em nome da desalienação, do centrar-se novamente, do retorno às origens, contudo, não teve, no período que se seguiria, senão a rejeição total das ciências sociais ocidentais, rejeição essa que se fundamentara desta vez sobre uma base, não mais nacionalista, mas religiosa.
Outro aspecto da fecundidade de Durkheim, nesta análise da instituição, refere-se à função de socialização, que me pareceu mais determinante do que aquela da reprodução. Numa sociedade saída da colonização, isto é, uma sociedade com uma estrutura de classe imatura e pouco nítida, o sistema de ensino parece ter um papel de produção das classes, dos grupos sociais, em vez da reprodução das desigualdades ou dos grupos sociais.

Minha terceira reflexão está estreitamente ligada ao desenvolvimento histórico da instituição. A ideologização da instituição, sua redefinição autocentrada, se fez em nome do marxismo - esquematicamente entre os anos da década de 1960 e fins da década seguinte - e, principalmente, com o suporte linguístico do francês. A referência a Durkheim no curso desse período foi frequentemente muito crítica, separando de alguma maneira o ponto de vista metodológico e confınando-o como estereótipo.

Concomitantemente, a arabização constituiu-se, ainda que no início as fileiras árabes reproduzissem, com algum tempo de atraso, o que ocorria nos setores francófonos, em oposição às fileiras afrancesadas, muito longe do marxismo. De modo que, com a arabização geral das ciências sociais, pode-se desenvolver um contradiscurso fundamentado sobre um durkheimianismo esmaecido - pelo que este podia ser abstraído de seu sistema teórico e de seus pressupostos políticos.

Com o refluxo do marxismo e a arabização generalizada, foi estabelecido um tipo de durkheimianismo sem Durkheim que se inscrevia de maneira muito ampla numa instituição à deriva. Mesmo assim, na conjuntura da época, a criação dessa expressão estereotipada do durkheimianismo mostrava-se como um contrapeso ao desenvolvimento de uma pedagogia do "obscurantismo". 
A crise multifacetada que atravessa a sociedade argelina, e que pareceria semelhante àquela da França no final do século passado - todas as coisas sendo iguais às avessas -, coloca na ordem do dia a questão da centralidade do sistema educativo na evolução da sociedade argelina. Com efeito, é no e a propósito do sistema de ensino que as contradições sociais apresentam-se mais radicais: são nestas questões, que o atravessam, o envolvem e lhe visam, que se definem e se esclarecem as relações de força na sociedade. Quer se trate da questão linguística, da mixité ${ }^{17}$, do conteúdo a dar para o ensino, aqui as clivagens são mais apaixonadas, mais nítidas. Essa centralidade pede, me parece, uma releitura de Durkheim à luz de exemplos de sociedades que não são completamente orgânicas, mas não são mais mecânicas.

J. C. FILLOUX - Agradeço aos três participantes por suas respectivas exposições. Agora, vocês podem, cada um dos três, nos brindar com suas observações acerca das intervenções dos outros dois colegas? Pierre Bourdieu...

P. BOURDIEU - Me parece que há um problema comum a Michel Eliard e Aïssa Kadri, que é aquele que se refere à função do sistema de ensino. A escola é produtora ou reprodutora de desigualdade? No caso da Argélia, a escola é produtora ou reprodutora desta desigualdade fundamental entre arabófonos e francófonos?

Sinceramente, creio que há um problema comum que gira em torno da noção de autonomia relativa. Na verdade, é certo que, como disse Michel Eliard, não pode- mos imputar somente ao sistema escolar a produção e a reprodução das desigualdades. Contudo, não podemos mais desculpá -lo completamente - se é que se trata de culpa isentá-lo de toda intervenção na reprodução e, por vezes, até mesmo no aumento das desigualdades iniciais. No caso da Argélia, a divisão entre francófonos e arabófonos preexiste ao funcionamento do sistema escolar, que se tornou uma questão vital nas lutas que assistimos ali, porque essa é a questão e o instrumento de todas as lutas pelo poder entre os detentores de espécies de capital linguístico e cultural diferentes: entre aqueles cujo capital linguístico e cultural foi adquirido no sistema escolar francês ou próximo e aqueles no qual o capital linguístico e cultural foi adquirido no ensino tradicional da medersa etc.

Concomitantemente, falar de autonomia relativa não faz o problema desaparecer, mas permite colocá-lo de outro modo: não temos que escolher em termos de tudo ou nada, não podemos imputar ao sistema escolar o que decorre das diferenças sociais preexistentes; na verdade, trata-se de perguntar - e isto, penso, é muito durkheimiano - em que a lógica do funcionamento do sistema escolar, lógica específica, irredutível à lógica da luta das classes cotidiana ou à lógica dos conflitos de valores do dia a dia, etc. em que esta lógica específica contribui, e para qual parte, à perpetuação ou à transformação das desigualdades ou das diferenças que existem exteriormente? Colocar o problema nesses termos fornece os meios de evitar as soluções em termos de alternativa: a culpa é de $a$..., a culpa é de b... Na minha avaliação, o caso da Argélia é particularmente interessante na medida em 
que, por razões históricas, o peso relativo do capital econômico na estrutura global do capital é relativamente mais frágil e, ao mesmo tempo, o peso do capital cultural e linguístico é particularmente grande, o que faz com que o banco central do capital sobre o qual desejamos colocar a mão seja o sistema escolar. E as lutas a propósito do sistema escolar revestem-se de uma violência extrema, porque elas têm por questão central o poder etc.

A. KADRI - Efetivamente, poderíamos levar em conta a autonomia relativa do sistema, mas me parece que com a Argélia temos um caso onde o sistema de ensino é muito fortemente dependente do político, completamente instrumentalizado pela política. Nesse caso, me parece, ele tem muito pouca autonomia. Além do que, à medida que é politicamente manipulado, ele se define como um lugar e um meio na produção de relações de forças políticas articuladas sobre os pertencimentos culturais; à medida que se torna o campo de uma "guerra de trincheiras” permanente, seus fundamentos institucionais se erodem.

P. BOURDIEU - Pouca autonomia, mesmo quando muito pequena, por pouco que seja, é muito importante. Há diferentes tipos de escolas: escolas francesas, escolas dos Pères Blancs $^{18}$, escolas árabes etc. Seguramente a dependência em relação aos poderes é considerável, mas mesmo (e esta é uma resposta um pouco fácil) os dirigentes inquietam-se sobre a reprodução de seus próprios filhos; há uma autonomia relativa do sistema escolar que não se submete às mãos e aos olhos do poder (pois a autonomia relativa apresenta gradações: a Medicina, por exemplo, na Argélia é muito mais autônoma que o ensino do árabe ou que o Direito). Por menor que seja, a autonomia relativa é sempre muito importante, porque é uma estrutura de liberdade em relação aos poderes, que devem fazer concessões à escola, mesmo que para poder manipulá-la.

J. C. FILlOUX - Por sua vez, o conceito de autonomia relativa é perfeitamente durkheimiano e, utilizando-o, não acredito que façamos uso de Durkheim sem recorrer a Durkheim.

P. BOURDIEU - 0 conceito também é marxista...

M. ELIARD - Sim, de fato. Não estou em desacordo a respeito da autonomia relativa da escola. Vou voltar ao assunto. Porém, uma vez que você pediu para me manifestar em relação ao que falaram meus colegas, desejaria fazer uma intervenção sobre um ponto levantado por Pierre Bourdieu. É verdade que podemos fazer análises durkheimianas que Durkheim não fez. Justamente, a propósito de $A$ evolução pedagógica na França, você afırma: é uma extraordinária análise de inércia do sistema de ensino. Isso é plenamente verdadeiro, mas é também verdade que há certas análises nessa obra que se referem à mudança, mas infelizmente Durkheim não as desenvolveu. Você mesmo tem alguns aspectos prolongados em suas obras. Quero falar das análises referentes às modificações das relações de classes. Quando Durkheim interpreta a revolução pedagógica da Renascença, por exemplo, ele diz que, naquela época, a distância entre as classes modificara-se, que a burguesia tornara-se mais rica, considera-

18. Missionários católicos franceses com atuação na África. (N.T.) 
va-se mais do que era, do lado da nobreza, e aspirava ao mesmo sistema de educação que esta. Aí, ele dá uma explicação da transformação do sistema educativo, relacionando-a às transformações sociais e, até mesmo, às transformações econômicas, o que é pouco habitual nele. Porém, fechado talvez em seus postulados organicistas (não sei se é uma boa explicação), ele jamais pôde desenvolver sistematicamente este gênero de análise. Ele para no meio do caminho de algum modo. De tempos em tempos há como que estalos luminosos sobre o vínculo entre as transformações sociais, em certas épocas, e as mudanças na educação. Ao mesmo tempo, seguramente, ele mostra que um sistema escolar não pode ser mudado à vontade. Seja dito de passagem, seria necessário recomendar este livro a cada novo ministro da educação nacional para que entenda que não se pode mudar a escola por decreto.

J. C. FILLOUX - Agora, se possível, desejaria que fossem formuladas questões pela plateia. Quem quer questionar um dos três participantes desta mesa?

Régis BERNARD - Desejaria fazer duas observações que, a meu ver, são também questões. Disseram aqui, já haviam dito durante a jornada, dirão sem dúvida amanhã, que Durkheim não fez muito, que não soube ver, por exemplo, a escola de classe etc. Certo, mas Durkheim não podia fazer tudo. Ele não estava, certamente, numa posição apropriada - epistemologicamente - que lhe permitisse ver o que tivemos que nos esforçar para ver muito mais tarde. Fundamentalmente, não estou seguro que possamos reprovar Durkheim por não nos falar de uma escola de classe no fim do século XIX e início do século XX. E não estou também seguro, pois não sou suficientemente conhecedor da matéria, que alguém o tenha feito naquela época. Não é só isso. Naquela época, era possível observar no campo da instituição escolar a manifestação das relações de classe? Esta continua a ser uma questão para mim e um convite para realizar a sociologia que Durkheim pôde ou que não pôde nos legar.

Para a minha segunda observação, desejaria retornar à ideia ainda há pouco enunciada por Michel Eliard a propósito dos 80\% de bacheliers ${ }^{19}$. Você nos disse que esse percentual era um ocultador, uma palavra de ordem vazia. Não compartilho inteiramente com este sentimento e, por estar me organizando para o início do ano letivo na universidade, posso mesmo afırmar que, se atualmente não alcançamos os 80\%, em alguns anos isso ocorrerá. Vemos chegar um número massivo de estudantes, recusamos a entrada de mais e mais, sobretudo vemos chegar à universidade jovens oriundos de meios sociais que até agora não estavam ali representados. Agora, eu bem sei que o $b a c^{20}$ profissional não é um $b a c$ C, que um $D_{E U G}{ }^{21}$ de Letras não é uma Escola Normal Superior etc. Não obstante, mesmo que

19. Aqueles que fazem o baccalauréat. (N.T.)

20. Abreviatura de baccalauréat. (N.T.)

21. 0 Diploma de Estudos Universitários Gerais (DEUG) foi criado em 1973 e é emitido para quem conclui os dois primeiros anos de estudos superiores nas seguintes áreas: Administração Econômica e Social, Artes, Ciências Humanas e Sociais, Ciências e Tecnologias, Ciências e Técnicas das Atividades Físicas e Esportivas, Economia e Gestão, Direito, Letras e Línguas, e Teologia. (N. T., a partir de informações do site francês do Ministère de L'éducation Nationale, de L'enseignement Supérieur et de la Recherche, acessado em 04 de dezembro de 2015). 
ocorresse um deslocamento das produções das desigualdades ou das reproduções das desigualdades pela escola, como queremos - e não discutirei sobre as causas e os efeitos - não se pode negar que as coisas modificaram-se, que a universidade mudou e, portanto, que as condições de acesso ao que chamamos ainda de ensino superior não são mais as mesmas. Esta mudança, talvez seja necessário registrá-la numa história que seria, sem dúvidas, aquela do deslocamento crescente do lugar crucial da separação dos indivíduos ou dos grupos de indivíduos pelo trabalho da escola. A partir desta perspectiva, parece-me, nos encontramos numa situação próxima àquela de Durkheim face à evolução pedagógica, que é um pouco a maneira como tentamos em Lyon tratar desses problemas: a questão da socialização e do processo que ela implica. Não estamos em um daqueles momentos privilegiados para o sociólogo - momento que experimento cotidianamente através de minhas responsabilidades universitárias -, momento de uma mudança radical, que não é novidade, mas um enésimo momento desta história que é, por sua vez, aquela que notadamente nos traçou Durkheim, em A evolução pedagógica na França, e igualmente aquela que traçaram Pierre Bourdieu e alguns outros nos anos 1960, o da escola reprodutora.

M. ELIARD - Sim, é complicada essa questão e, talvez, o que vou dizer pareça-lhe repulsivamente retrógado. Não posso me furtar de achar demagógica essa ideia que foi exposta. Afırmar: "é necessário que 80\% de uma classe de concludentes alcance o nível do baccalauréat", primeiramente, isto não pode se referir ao mesmo baccalauréat que conhecemos, é impossível. Consequentemente, penso que, por meio desta proposição, tenta-se transformar em problema es- colar o que é, na verdade, um problema da sociedade. Quero dizer com isso que, como nossos governantes manifestam uma incapacidade evidente para regrar os problemas do emprego, eles transferem os problemas para a escola, exigindo que esta faça alguma coisa que produza a ilusão de regrar o problema da desigualdade.

0 fato, por exemplo, de fazer desaparecer gradativamente uma série, como o ensino técnico de curta duração, que permitiu, durante um período bastante longo, aos alunos, filhos e filhas de operários, terem acesso às profissões qualificadas, coloca um grave problema. Dizem-nos que, ao prolongarmos a escolaridade, moderniza-se aquele setor. Não estou convencido disto. Parece-me que esta palavra de ordem dos 80\% mascara uma acentuação das disparidades de escolarização entre as classes sociais. É por isso que insisti ainda há pouco sobre a ideia da escola justa, equitativa. Há o livro de Jean-Louis Derouet que se intitula Escola e justiça. Não compartilho as soluções que ele propõe, em particular quando avalia que, com a descentralização, a escola poderia tornar-se mais justa. Porém, esta noção de justiça me parece que deve ser recolocada em primeiro plano.

Jean-Manuel de QUEIROZ - Tenho uma observação e três questões. Minha observação é a seguinte: parece-me importante que estabelecer como objetivo de uma sociedade esse tipo de norma é introduzir um novo princípio de divisão, o qual me afıgura, com efeito, que há um paradoxo no que poderíamos chamar de escola democrática: quanto mais ela se democratiza no sentido de que muito se abre aos novos públicos, setores para os quais outrora estava fechada, mais aqueles que não conseguem ter êxito encontram-se, eu diria, estigmatizados. Isto é, 
numa perspectiva de que $80 \%$ de uma classe de concludentes alcance o nível do baccalauréat, os 20\% restantes não ficam somente longe da média, mas também longe da norma. No fundo, quanto mais democratizada a escola, mais aqueles que não conseguem se submeter à norma, isto é, ao que é considerado como um nível de escolarização normal, encontram-se numa situação pior do que quando a escola era menos democrática. Essa era minha observação sobre os efeitos dos novos princípios de divisão.

Minhas questões são as seguintes. A primeira é esta: é que tanto uns como outros de vocês estão de acordo em creditar a Durkheim o princípio do reconhecimento intuitivo e prático, mas não explícito, da autonomia relativa da qual falava Pierre Bourdieu, que me parece, pelo menos para mim, presente no estado prático, notadamente em $A$ evolução pedagógica na França, no sentido de que vemos que a intensificação dos diferentes modelos escolares é uma intensificação que tem sua lógica própria, mesmo se Durkheim coloca em relação - o que é completamente inédito - as mudanças escolares com as necessidades civis da sociedade; ao mesmo tempo, me parece, há um ritmo próprio dos paradigmas culturais e pedagógicos.

Uma segunda questão sob a forma de espanto, mas talvez de um mau espanto, no sentido em que as coisas talvez sejam tão evidentes que não haja necessidade de falar delas. É que esperava um pouco, tanto de uns quanto de outros, que vocês nos dissessem que há na sociologia da educação contemporânea uma abordagem durkheimiana oblíqua, curiosa, como explicou Bourdieu, mas sobre um objeto passivo que é aquele das desigualdades no sentido em que, com efeito, a sociologia contemporânea da educação foi amplamente uma sociolo- gia da escolaridade desigual e das chances desiguais de escolarização, algo completamente distante de Durkheim e do que ele disse da escola. É completamente estranho a Durkheim, mais ainda se tomamos os conceitos de reprodução - porque, no limite, se Durkheim os empregou, foi num sentido positivo , no sentido que deve ser para ele, com efeito, como as sociedades se reproduzem, enquanto, para nós, o conceito tem antes de tudo uma valência negativa, talvez mais, mas esse é um outro problema. Portanto, é inteiramente estranho a Durkheim e, ao mesmo tempo, é fiel/infiel a Durkheim, simplesmente durkheimiano, na medida em que Durkheim nos legou algo que é, no fundo, aprendermos a nos surpreender e objetivar objetos nas suas formas de ser. Diria que, paradoxalmente, o modelo da sociologia das desigualdades escolares tem em Durkheim um modelo que é o suicídio. Isto é, Durkheim inovou ao sociologizar um objeto, um fato social, ao qual anteriormente se atribuíam causas individuais e psicológicas, como até num período recente as performances escolares eram atribuídas às causas psicológicas e individuais (os dons, o dotado, o não dotado etc.). Portanto, fiquei um pouco surpreso que este fato significativo da fidelidade/infidelidade a Durkheim não tenha sido mencionado.

Se me lembro, minha terceira questão é sobre uma possível contribuição de Durkheim. Vemos claramente na sociologia da educação, e talvez mais ainda em suas tendências recentes, a importância atribuída à subjetividade dos atores, à representação que eles fazem de seu espaço de possíveis etc. Ora, Durkheim diz isso - porém, fala também disso noutro momento, a propósito de outra coisa, como François Cardi nos lembrou nesta manhã, de maneira que nos escandaliza além da conta; Durkheim subli- 
nha que se o horizonte do operário se amplia quando se lhe fornece uma cultura geral, então ele vai ser infeliz, não se realizará mais no espaço dentro do qual está inserido, não desejará mais permanecer no seu lugar. Há, ainda, mesmo que seja de um modo um pouco enviesado, uma maneira para Durkheim nos indicar a que ponto o sentido do lugar e da sociologia do ator é importante. Vocês concordam com esta interpretação?

P. BOURDIEU - Estou muito contente pelo que você disse porque é uma outra maneira de dizer o que procurara dizer pela parábola das categorias do entendimento, isto é, que não se é jamais tão durkheimiano a não ser quando faz-se coisas que Durkheim não fez. Neste paradoxo, vis-à-vis à fidelidade que você ilustrou magnificamente, penso a propósito dos problemas da igualdade e da desigualdade. As questões que foram colocadas concernentes à função reprodutora do sistema escolar são questões durkheimianas em espírito e, contudo, Durkheim não as formulou. Todos os grandes pensadores têm acidentes de pensamento em que não estão à altura deles mesmos. Há momentos em que Durkheim não é durkheimiano. É muito importante, creio, para a prática, para o que se faz com Durkheim: tal passagem de Durkheim pode-se criticá -la em nome do próprio Durkheim.

Estou contente que você tenha dito isso e, ao mesmo tempo, desejaria voltar um segundo ao problema dos $80 \%$, que é muito importante, mas difícil de abordar improvisando em condições que não são perfeitas, já que necessitaria pesar cada palavra.

Estou plenamente de acordo com Michel Eliard por dizer que a palavra de ordem dos 80\% é essencialmente demagógica, isto é, falsamente democrática. Dito assim, fica parecendo uma tomada de posição política, mas podemos analisar este aspecto cientificamente, por meio dos efeitos desta palavra de ordem. Em certo sentido, esta palavra de ordem não tem senão muito sucesso (talvez porque as únicas palavras de ordem políticas bemsucedidas sejam aquelas que aceleram as tendências imanentes do corpo social). Necessitaria que os ministros aprendessem que não se muda a sociedade por decreto. Isto dito, eles podem mudar a sociedade por decreto quando percebem poder fazer advir por decreto o que está em vias de se desenvolver, de suceder (é o famoso paradigma de Jean-Cristophe que, no romance de Romain Rolland, ordena as nuvens que estão à direita para irem para a direita). Um ministro que ordena a um sistema escolar que vá na direção de permitir o acesso muito mais intenso de um número muito maior de pessoas, de fazer o que está em curso de se realizar, sem nada prever sobre as consequências da aceleração que vai dar num processo que será, em todo o caso, muito difícil de controlar, muito difícil de matrizar, age de uma forma demagógica muito perigosa. Com efeito, produzir uma democratização aparente é produzir o contrário do que se está parecendo desejar. Não estou em condições em que possa fazer uma demonstração completa, mas estou plenamente de acordo com o que disse Michel Eliard ainda há pouco. Seria necessário muito se refletir a respeito do que se fez estabelecendo essa instrução e as consequências práticas sobre a conduta dos conselhos de classe, dos pais, dos diretores ou dos chefes dos estabelecimentos que devem sofrer com a pressão dos pais dos alunos, dos professores que estão subordinados à demanda da passagem à classe superior etc. etc., todas as consequências que isso pode provocar. 
A. KADRI - Desejaria acrescentar uma palavra sobre a autonomia relativa, pois creio que me fiz mal compreender. Citei Durkheim na medida em que este princípio da autonomia relativa me parece essencial e fundamentalmente durkheimiano. Ora, em conjunturas precisas, em momentos históricos precisos, sobretudo em sociedades que conheceram fortes imposições exógenas, há, me parece, um problema. Tratando-se da Argélia e de seu sistema de educação hoje, observo que há um fato de desinstitucionalização na medida em que a Instituição está completamente penetrada pelos valores - legitimação extrauniversitária, enriquecimento fácil e sem causa - de uma sociedade rentista, não fundamentada sobre o trabalho produtivo. Esse movimento de investimento no sistema de ensino pareceu tanto mais perturbador que a história da Instituição, que não foi estável e que caminhou de reformas em reformas. Esse processo, conjugado a uma exacerbada politização das transformações pedagógicas, enfraqueceu a Instituição no plano das regras gerais de funcionamento e a reduziu ao grau zero. Portanto, estamos ali numa fase de ruptura e o problema é colocado pela transmutação do sistema de ensino: em qual direção o sistema de ensino caminha? Rumo a uma inversão e ao retorno às formas educativas degradadas ou, melhor, a um sistema que se refina e cria outras hierarquias, por exemplo, a formação pelo estrangeiro?

J. C. FILLOUX - Bem, há outras questões?

M. ELIARD - Posso falar uma palavra também sobre autonomia...

J. C. FILLOUX - Certamente, pois a autonomia tornou-se um conceito central...
M. ELIARD - A propósito disso, desejaria colocar uma questão a Pierre Bourdieu. Gostaria de lhe perguntar se, hoje, ele manteria tais quais suas análises de $A$ reprodução, que desenvolvem a famosa passagem da introdução de Halbwachs à A evolução pedagógica na França, na qual ele explica que a organização pedagógica parece mais conservadora e tradicional que a própria Igreja. Eu me pergunto se essas análises não são exageradas, justamente, quando colocadas ao lado da função conservadora da escola, mas num sentido negativo, o que oculta o fato de que conservar a cultura, sobretudo hoje talvez, para transmiti-la às gerações sucessivas, é uma função positiva, extremamente positiva. Hoje, você falaria sobre esses aspectos da mesma maneira?

P. BOURDIEU - Compreendo que você me faça essa questão, mas estou um pouco constrangido para responder. Isto me coloca na posição de exegeta de mim próprio... Diria somente que há muitas frases de $A$ reprodução que eu não reescreveria. É um livro que foi útil num momento onde se tratava de tentar fixar de alguma maneira um certo número de conceitos formulados naquele momento. Não o renego: era importante que se esforçasse para ter conceitos tão rigorosos quanto possíveis (era a época em que se falava em termos de mutação, as mídias estavam em mutação, tudo estava em mutação e os conceitos frequentemente eram também mutantes, conceitos elásticos, suaves, malfeitos, falava-se sobre qualquer coisa). Portanto, havia um esforço para falar das coisas de maneira um pouco rigorosa etc., e penso que era útil, mas provisoriamente, a um certo momento, com a certeza de que isso seria ultrapassado. Essa é a primeira resposta. 
A segunda é que sempre há os efeitos de conjuntura, e nem sempre há como nos dirigirmos noutro sentido. Isto é, como a apresentação dominante do sistema escolar, nas concepções dos pais, dos professores etc., era a escola libertária, era importante acentuar essa função conservadora, de maneira um pouco excessiva, mas evidentemente o que você disse estava presente. Por exemplo, um dos problemas, aquele da conservação dos conhecimentos científicos: a escola não é conservadora quando ela conserva os conhecimentos científicos. Teria inúmeras correções a fazer, mas é de Durkheim que estamos a falar... Em todo caso, acho que atribuímos muito aos autores canônicos, aos pais fundadores e, sobretudo, esperamos demais deles. Apesar de tudo, fizemos progresso.

J. C. FILLOUX - Queria pôr uma pequena questão concernente à concepção de violência que é utilizada por Durkheim. Será que há uma relação, por exemplo, entre o que se falou esta manhã sobre a autoridade do professor e o que foi dito também a propósito do Japão, em razão de Durkheim, pois há o fato de ele ter sido muito bem acolhido naquele país já que sua sociologia corresponde ao tipo da sociedade japonesa - aqui, houve uma comunicação de Joëlle Plantier sobre este assunto ${ }^{22}$. Durkheim fala em alguma parte sobre violência pedagógica, ele lembra a "megalomania escolar". 0 que eu me perguntava era se haveria, aos olhos de Pierre Bourdieu, mas também aos de Michel Eliard, uma relação entre o que se poderia chamar de violência simbólica e violência pedagógica. Parece-me que há al- guma relação entre essas duas coisas. Ora, no momento, há ainda o problema da violência na escola.

P. BOURDIEU - Tentarei falar algumas palavras sobre essa questão. Na verdade, com toda honestidade, não li esses textos de Durkheim, mas penso que podemos, através do que conheço (sobre as reflexões de Durkheim da autoridade etc.)... podemos fazer uma aproximação entre minha análise da violência simbólica e o que afırmava Durkheim sobre a autoridade pedagógica. Porém, penso que Durkheim não teria jamais empregado este vocabulário, talvez por otimismo pedagógico, por otimismo republicano etc., e é verdade que empregar a noção de violência simbólica a propósito da escolha pedagógica parecia um pouco excessivo. Contudo, me parece importante empregar a palavra excessivo para despertar as pessoas que estão adormecidas na indiferença.

Fazíamos alusão há pouco a este efeito durkheimiano, que consiste em dessacralizar o banal, em interrogar o evidente etc. Penso que a relação pedagógica é uma das relações sociais mais fundamentais na medida em que, como a relação pais-filhos, mãe-filha, a relação escolar faz parte das aprendizagens primárias, ao mesmo tempo em que temos dificuldade em pensar algumas dessas convenções. Portanto, creio que foi importante insistir sobre essa violência afirmando, ao mesmo tempo, que era uma violência de uma forma completamente particular, que é um caso particular de uma classe de violências simbólicas, como a violência entre os sexos ou, em certas relações coloniais, entre o colonizador e o coloniza-

22. No segundo dia das Jornadas de estudo sobre Durkheim e a sociologia da educação, Joëlle Plantier apresentou o seguinte comunicado: "Durkheim e a sociologia japonesa da educação". (N.T.) 
do, isto é, uma violência que se exerce com a cumplicidade extorquida daqueles que a ela se submetem.

Penso que essa análise feita a respeito da relação pedagógica foi muito útil para compreender as relações sociais que não se deixam pensar segundo as categorias ordinárias da violência. A relação pedagógica é o caso por excelência de violência simbólica, uma vez que é onde se procura menos exercer a violência. Estamos num registro que é inteiramente antitético à violência. Ora, penso que há uma forma muito sutil de violência. Retrospectivamente, avalio que é uma palavra que reempregaria. É um forte golpe contra os bons sentimentos.

Éric PLAISANCE - Vejo a contribuição de Durkheim à análise da educação em termos do fato social em relação com outros fatos sociais ou, se preferirem, à análise da educação em termos de sistema de instituições e sistema de práticas. Porém, vejo também uma outra dimensão sobre a qual se insiste um pouco: Durkheim, em sua obra póstuma A educação moral, define a classe como um microcosmo social, exatamente como uma "pequena sociedade... [que possui]... uma moral própria, em relação com o número e a natureza dos elementos que a compõem e em relação com a função de que ela é o órgão”. Neste sentido, ele parece anunciar os desenvolvimentos recentes da sociologia da educação, que abrem a "caixa preta" do estabelecimento escolar ou da classe para analisar os processos que ali ocorrem. Portanto, gostaria de lhe perguntar como você reage a essa proposição de Durkheim sobre a classe?

P. BOURDIEU - A leitura que você faz de Durkheim chama atenção, e com razão, sobre o fato de que a maior parte dos estudos consagrados à educação deixaram subsistir uma espécie de caixa preta e ignoraram o que se passa no interior deste microcosmo social que é a classe. Para compreender os efeitos, ainda mal conhecidos, que ocorrem no interior deste microcosmo, não basta analisar as estruturas mentais dos professores ou os métodos pedagógicos que eles empregam (o que constituiu um progresso decisivo frente aos estudos que se contentavam em estabelecer a relação, sem outra mediação, das características sociais dos alunos e seus resultados escolares). Também urge atualizar as representações (diferenciadas ou, ao contrário, globalizantes) que os professores fazem do conjunto dos alunos subordinados às suas ações pedagógicas e as estratégias (privilégio concedido a quem se encontra à frente da classe ou que tem vontade de "conduzir" toda a classe, por exemplo) que empregam para assegurar a transmissão do saber. Alguns trabalhos notadamente aquele de Sylvain Broccolichi - estão em curso e deverão esclarecer esses processos obscuros e muito importantes.

Jean ESTĖVE - Desejaria simplesmente indicar que me parece que, na época contemporânea, talvez haja ausência de fidelidade com a instigação durkheimiana de falar unicamente, como já ocorreu de fato, a propósito da sociologia da educação, da sociologia escolar. A formação continuada e seu desenvolvimento explosivo nos últimos anos, a educação permanente da qual se falava desde muito tempo, em muitos países da Europa o encaminhamento de experiências e de tentativas de educação comunitária, tudo isso me parece constituir os elementos de real importância que nos interditam, se nós queremos permanecer fiéis à impulsão durkheimiana, de nos ater a uma sociologia da educação que seja uma sociologia da classe no sentido em que o termo veio a ser empregado. 
M. ELIARD - Aqui, ninguém reduziu a sociologia da educação à sociologia da classe. Porém, não sei se Durkheim tratou da formação permanente.

(Intervenção não identificada) - Minha questão é dirigida a Michel Eliard. Você não acha que Durkheim fica numa posição bastante longe da escola, mas não se poderia dizer que ele é prisioneiro de uma certa situação institucional? Ele leciona na Sorbonne, que lhe serve igualmente de tribuna!

M. ELIARD - Sim, creio que há aí uma explicação possível. A posição que Durkheim ocupava na Sorbonne, mas também do lado dos políticos da Terceira República, pode explicar, em larga medida, suas posições teóricas. Porém, a explicação também pede que se olhe para o fato de que sua teoria geral, seu sistema de pensamento muito organicista, sua preocupação de ver realizarse o consenso, o impediram de desenvolver um certo número de análises nas quais as relações de classes e suas modificações aparecessem como explicação das mudanças.

Penso também que há diversos Durkheim. Há um Durkheim conservador e um Durkheim progressista. Foi este último que ajudou a convencer Jaurès de se posicionar em defesa de Dreyfus ${ }^{23}$. É uma explicação sobre o lugar que ele ocupava entre os intelectuais da época. Há uma série de proposições que Durkheim formulou anteriormente e que eram muito próximas da corrente socialista, mas que não se reencontram em sua concepção geral da educação. Isto decorreria do fato de que a educação não era sua prioridade? Em todo caso, sua preocupação principal, que era contribuir para reorganizar a sociedade sobre uma base corporativa, o levou a privilegiar a função da educação moral da escola, diferente de Condorcet que insistia exclusivamente sobre a instrução.

P. BOURDIEU - Se posso prolongar, penso que o que você disse é verdadeiro. Acrescentaria que esse é um tema que foi muito repetido a propósito dos filósofos alemães pensadores do Estado etc. Acho que um pensador do Estado - um funcionário do pensamento - deve à sua função a reflexividade. É por isso que insistira, inicialmente, sobre a reflexividade que é necessária para evitar que se aceitem todos os tipos de pressupostos, completamente inconsistentes. Para me fazer compreender, dou como exemplo um livro de Thomas Bernardt, cujo título é Antigos mestres, onde há uma tirada sobre o pensador do Estado que tem um pensamento do Estado. Avalio que não há pensamento do Estado mais típico que o pensamento durkheimiano do Estado, que é uma espécie de hegelianismo conferindo aos pensadores funcionários do Estado uma função de totalização. Para mim, isso é muito atual: avalio que hoje três quartos dos problemas sobre os quais trabalham os sociólogos são inspirados pelo Estado, não somente por meio dos contratos e do dinheiro dele proveniente, mas também através dos problemas que ele impõe. Isso coloca o problema da autonomia do pensador em relação ao Estado e ao pensamento

23. Eliard refere-se ao processo que foi movido contra o capitão de artilharia do exército francês Alfred Dreyfus, acusado de ser espião alemão, sendo por isso condenado em 1894. A partir de 1897, quando as irregularidades do processo começaram a ser conhecidas, iniciou-se uma campanha pela sua revisão na qual participaram professores, escritores e artistas. Em Bordeaux, Durkheim foi um dos lideres da campanha. (N.T.) 
do Estado. É por isso que defendo que a reflexividade, isto é, o fato de fazermos retornar sobre nós mesmos as questões que nós formulamos a respeito dos outros, é relativamente capital. É neste lado que se afirma a liberdade.

J. C. FILLOUX - Agradeço aos participantes desta mesa-redonda ${ }^{24}$. roteiro enviado por Jean-Claude Chamboredon e que orientaria sua intervenção. Como se trata somente de ideias e temas a serem desenvolvidos oralmente, achamos por bem excluí-lo da tradução. (N.T.) 
